\title{
ОСОБЕННОСТИ ПЕРЕВОДА НА РУССКИЙ ЯЗЫК АНГЛИЙСКИХ ФРАЗЕОЛОГИЗМОВ
}

\section{FEATURES OF THE TRANSLATION OF ENGLISH PHRASEOLOGICAL UNITS INTO RUSSIAN}

\section{A. Kudzayeva \\ Z. Gazzayeva \\ U. Kolieva}

Summary: This article examines the features and difficulties of translating English phraseological units into Russian. This topic seems to be very relevant, since the language, like a living organism, is constantly developing and changing, and it is necessary to monitor all these changes in a timely manner so as not to experience difficulties when translating texts, regardless of their stylistic affiliation. The translation of phraseological units is, as a rule, the greatest difficulty, since these speech units are bright and figurative, and it is necessary not to lose this imagery and colorfulness by translating them into Russian.

Keywords: phraseological units, translation, stylistics, imagery, expressiveness, linguistic techniques.

\author{
Кудзаева Аксана Гаджихановна \\ к.п.н., дочент, Северо-Осетинский государственный \\ университет им. К.Л. Хетагурова, г. Владикавказ \\ juliatibilova@mail.ru \\ Газзаева Зарема Амирановна \\ к.n.н., дочент, Горский государственный аграрный \\ университет, г. Владикавказ \\ Колиева Ульяна Хазбиевна \\ Старший преподаватель, Горский государственный \\ аграрный университет, г. Владикавказ
}

Аннотация: В настоящей статье исследуются особенности и трудности перевода на русский язык английских фразеологических единиц. Данная тема представляется весьма актуальной, поскольку язык, подобно живому организму, постоянно развивается и изменяется, и необходимо своевременно отслеживать все эти изменения, чтобы не испытывать сложности при переводе текстов, вне зависимости от их стилистической принадлежности. Перевод фразеологизмов представляет, как правило, наибольшую трудность, так как данные речевые единицы являются яркими и образными, и необходимо не утратить эту образность и красочность, переводя их на русский язык.

Ключевые слова: фразеологические единицы, перевод, стилистика, образность, экспрессивность, лингвистические приемы.

акунарным, а концепт может при этом присутствовать и полностью совпадать по значению с лакунарной единицей. При переводе таких фразеологизмов надо использовать языковые средства с аналогичным значением в переводящем языке, либо использовать дескриптивный перевод, либо калькирование. Главное, чтобы читателям перевода был понятен образ, на основе которого построен фразеологизм исходного языка [4, с. 86].

Подобные фразеологизмы имеются как в русском, так и в английском языке. Их примером могут стать такие выражения, как бедный родственник - a poor relation; go nuts - сойти с ума, выжить из ума; hit the high spots - затрагивать только основное, говорить об основном; акцентировать внимание на наиболее важном.

Следует отметить, что, в отличие от приведенных, ФЕ с народно-культурным элементом в своей структуре представляют довольно малочисленную группу в обоих языках. Они являются национально особенными, так как в их структуре присутствуют слова, характерные для этой народности. Речь может идти об объектах или событиях, о которых знают лишь представители конкретного народа. Данные ФЕ могут быть представлены разнообразными гидронимами, антропонимами, топонимами, свойственными определенному государству [2, с. 99]. 
В качестве примера подобных ФЕ можно привести фразу Вяземская лавра. Это выражение означает «притон, место сбора людей, которые ведут аморальный образ жизни». Данная ФЕ появилась благодаря князю Вяземскому, чей дом в Петербурге имел нехорошую славу.

Экспрессивность и иронический окрас ФЕ получают благодаря компоновке определенной фамилии с переосмысленной лексемой «лавра» - «мужской православный монастырь».

Итак, в народной специфике ФЕ могут выражаться и история, и разнообразные культурные традиции, привычки, менталитет нации, свойственные ей изначально. Рассмотрим пример.

В русском языке ФЕ «сам себя высек» относится к человеку, который сам нарвался на неприятности, нанеся самому себе вред собственными словами и поступками. Эта ФЕ появилась в середине XIX столетия после того, как была издана комедия Н.В. Гоголя «Ревизор». В тексте комедии городничий сообщает Хлестакову, что унтерофицерша соврала, что она сама себя высекла.

Необходимо иметь в виду, что в оригинале и переводе могут присутствовать ФЕ, имеющие практически тождественное значение, в основе которых лежат различные образы, с ярко выраженным народным характером. Примером может послужить русский фразеологизм «отправиться в Тулу со своим самоваром» и английский «carry coals to Newcastle». В английском варианте мы имеем дело с народно-специфическими топонимами, при этом оба варианта - и русский, и английский - имеют идентичное значение. Английская версия в буквально переводе означает «отвозить уголь в Ньюкасл», т.е. в местность, где его и без того в избытке [1, с. 125].

При этом не следует преувеличивать значение народно-культурной составляющей во фразеологическом видении мира различными народностями. Фразеологические системы всяких сравниваемых языков, в данном случае это русский и английский, всегда присутствуют в большом количестве интернационализмы и ФЕ, отражающие общечеловеческое знание о характеристиках окружающей действительности. Их разная образная база обусловлена не столько культурной идентичностью, сколько несоответствием средств вторичной номинации в разнообразных языках [7, с. 214].

Лингвистические приемы, используемые при переводе фразеологизмов, базируются на неделимости и слитности компонентов фразеологических единиц. Анализ литературы по данному вопросу позволяет выделить следующие виды перевода ФЕ:

1. Нефразеологический перевод.

Суть данного перевода заключается в передаче смысла ФЕ лексическими средствами языка перевода. Этот метод применяется тогда, когда в языке перевода невозможно найти фразеологический эквивалент или аналог. На наш взгляд, такой перевод можно использовать только в крайних случаях, поскольку он влечет за собой потерю экспрессивности и метафоричности фразеологизма и не является, вследствие этого, полноценным.

2. Лексический перевод.

Данный метод используется тогда, когда в языке перевода понятие, выраженное в исходном языке фразеологизмом, передается с помощью одного слова или словосочетания. Такой способ перевода позволяет точно передать семантику $Ф \mathrm{E}$, но главное, попытаться сохранить его образность.

3. Калькирование.

Этот способ перевода подразумевает буквальный перевод и используется в тех случаях, когда другие приемы перевода не позволяют передать эмоционально-экспрессивное и семантическистилистическое значение фразеологизма. Калькирование часто используют и для того, чтобы «оживить» образ, заключенный во фразеологизме, если это невозможно сделать другими лексическими средствами языка-реципиента.

4. Описательный перевод.

Данный метод перевода представляет собой толкование фразеологических оборотов. К нему прибегают в тех случаях, когда фразеологизмы исходного языка вообще не имеют эквивалентов в языке перевода [3, с. 102]. Он работает только в контексте, так как при изменении контекста может оказаться, что не все элементы текста были корректно переданы.

5. Контекстуальный и выборочный перевод.

К контекстуальному переводу обращаются в тех случаях, когда отсутствуют другие эквиваленты и аналоги и фразеологизм приходится передавать нефразеологическими средствами.

При выборочном переводе, который можно рассматривать как обязательный первичный этап перевода устойчивого сочетания, выбирают варианты, синонимы общепринятых словарных соответствий. Такой перевод выбирают, когда этого требует контекст, т.е. когда общепринятые соответствия или фразеологические эквиваленты не подходят по стилю или колориту [7, с. 34].

Какой бы прием ни выбрал переводчик для перевода ФЕ, главное требование - перевод должен быть эквивалентным, т.е. по возможности не иметь пропусков, изменений, искажений, добавлений. Но это не означает, что следует придерживаться буквализма. Напротив, в современной теории перевода опущения, замены, перестановки и добавления отмечаются как приемлемые способы достижения эквивалентности. Надо понимать, 
что при таких трансформациях может преобразовываться не только форма, но и содержание исходного фразеологизма, поэтому они называются формально-семантическими. Можно сказать, что данные трансформации должны дополнять, а не полностью заменять основные принципы переводческой стратегии [8, с. 117].

Переводчик, мастерски владеющий всеми перечисленными видами трансформаций, осуществляет более совершенный перевод. При этом надо помнить, что выбор того или иного средства зависит от многих факторов, среди которых достижение эквивалентности и образности при сохранении семантического значения и экспрессивно-эмоциональной окраски занимают первое место [5, с. 91].

Рассмотрим особенности перевода образных и необразных фразеологизмов

В научной литературе выделяют четыре основных способа передачи образных фразеологизмов:

1. полное сохранение образа;

2. частичное изменение образа;

3. полная замена образа;

4. снятие образности.

Способом с полным сохранением образности переводятся обычно фразеологизмы самой различной структуры, имеющие интернациональный характер. Это и застывшие метафоры, и перифразы, и крылатые выражения, и пословицы, и поговорки, а также заимствования. Например: blue stocking - "синий чулок"; dead letter "мертвая буква"; the lion 's share - "львиная доля"; in the seventh heaven - "на седьмом небе"; body and soul - "душой и сердцем"; to play with fire - "играть с огнем"; to gild the pill - "позолотить пилюлю".

При втором способе, при полном сохранении образной основы, фразеологизм подвергается определенным изменениям лексического или грамматического характера. В частности, может заменяться один из компонентов словосочетания, являющийся образным компонентом, заменяется близким ему или вспомогательным компонентом. Например: in the dead of night - "глубокой ночью"; in broad daylight - "средь бело дня"; cannon fodder ( food for powder ) - "пушечное мясо"; a diamond of the first water - "бриллиант чистой воды". В этих фразеологизмах происходит замена единственного числа множественным, инфинитив заменяется глаголом в личной форме и т.д.

Наибольшую трудность, но одновременно и наибольший интерес в процессе работы представляют фразеологизмы, при переводе которых происходит полная замена образной основы. Такая трансформация чаще всего обусловлена необходимостью сохранения экспрессивной окраски, которая подчас важнее, чем передача функционально-стилистической стороны фразеологизма. На практике осуществить такой перевод бывает довольно трудно, так как национальное своеобразие фразеологизма передается и в экспрессивной, и в стилистической окраске [2, с. 104].

Случай, когда переводчик прибегает к снятию образности, пожалуй, самый нежелательный, так как при этом теряется выразительность. Лучше попытаться найти другой способ перевода.

Существуют в языке и фразеологизмы, изначально лишённые образности. Для них характерна сложная семантика, так как эмоционально-экспрессивное значение сочетается с субъективной оценкой действительности. Эти выражения являются модально-вводными словами и выражениями одновременно. Примерами ФЕ такого типа в английском являются for that matter; for that matter of that; if anything. Для адекватного перевода таких ФЕ особенно важен учет контекста. В зависимости от контекста данная группа ФЕ имеет широкий семантический диапазон.

Проанализировав существующие в современном языкознании мнения относительно сущности и характеристик фразеологических единиц, мы считаем наиболее полным и корректным определение Н.М. Шанского, в соответствии с которым под фразеологизмом понимается воспроизводимая в готовом виде языковая единица, состоящая из двух или более словкомпонентов, имеющая постоянный состав, значение и структуру [8, с. 122].

Подводя итоги статьи, следует отметить следующее.

Основную трудность при переводе ФЕ создают следующие моменты:

1. ФЕ имеют чисто внешне сходство со свободными сочетаниями. Чтобы избежать грубых ошибок при переводе, надо уметь различать ФЕ в тексте.

2. В английском и русском языках может быть ассоциативная схожесть ФЕ, когда при полном совпадении формы их значения не совпадают (ср. англ. tolead by the nose всецело подчинить и русск. водить за нос)

3. Английские ФЕ более недифференцированы стилистически и обладают многозначностью (ср. англ. To take the floor в политике означает выступить на собрании, а в быту - пойти танцевать).

Основными способами перевода ФЕ являются:

1. Перевод с использованием эквивалентного фразеологизма.

2. Замена образа при сохранении семантической близости.

3. Калькирование (дословный перевод). 


\section{4. Перевод без сохранения образа.}

Поскольку фразеологизмы в массе своей эмоционально и стилистически окрашены и отражают национальное своеобразие, их перевод вызывает определен- ные трудности. Для точной передачи сути фразеологизма важен учет контекста. В значительной степени осложняет перевод английских фразеологизмов и их многозначность и многоплановость.

\section{ЛИТЕРАТУРА}

1. Агопова Р.А. Проблемы сопоставительной фразеологии английского и русского языков: Учебное пособие для студентов. - Казань: КГУ, 2014.

2. Амосова Н.Н. Основы английской фразеологии. - М.: ЛИБРОКОМ, 2016.

3. Голикова Ж.А. Лексикология и фразеология современного английского языка. Практикум. - Мн.: Новое знание, 2006.

4. Дубровин М.И. Русские и английские идиомы. - М.: ИЛБИ, 2018.

5. Иванова Е.В. Лексикология и фразеология современного английского языка. - М.: Академия, 2017.

6. Кунин А.В. Курс фразеологии современного английского языка. - Дубна, 2015. - 170 с.

7. Федуленкова Т.Н. Английская фразеология. - Архангельск, 2018.

8. Шанский Н.М. Стилистическое использование фразеологических оборотов// Фразеология современного русского языка. - СПб.: ЛКИ, 2006.

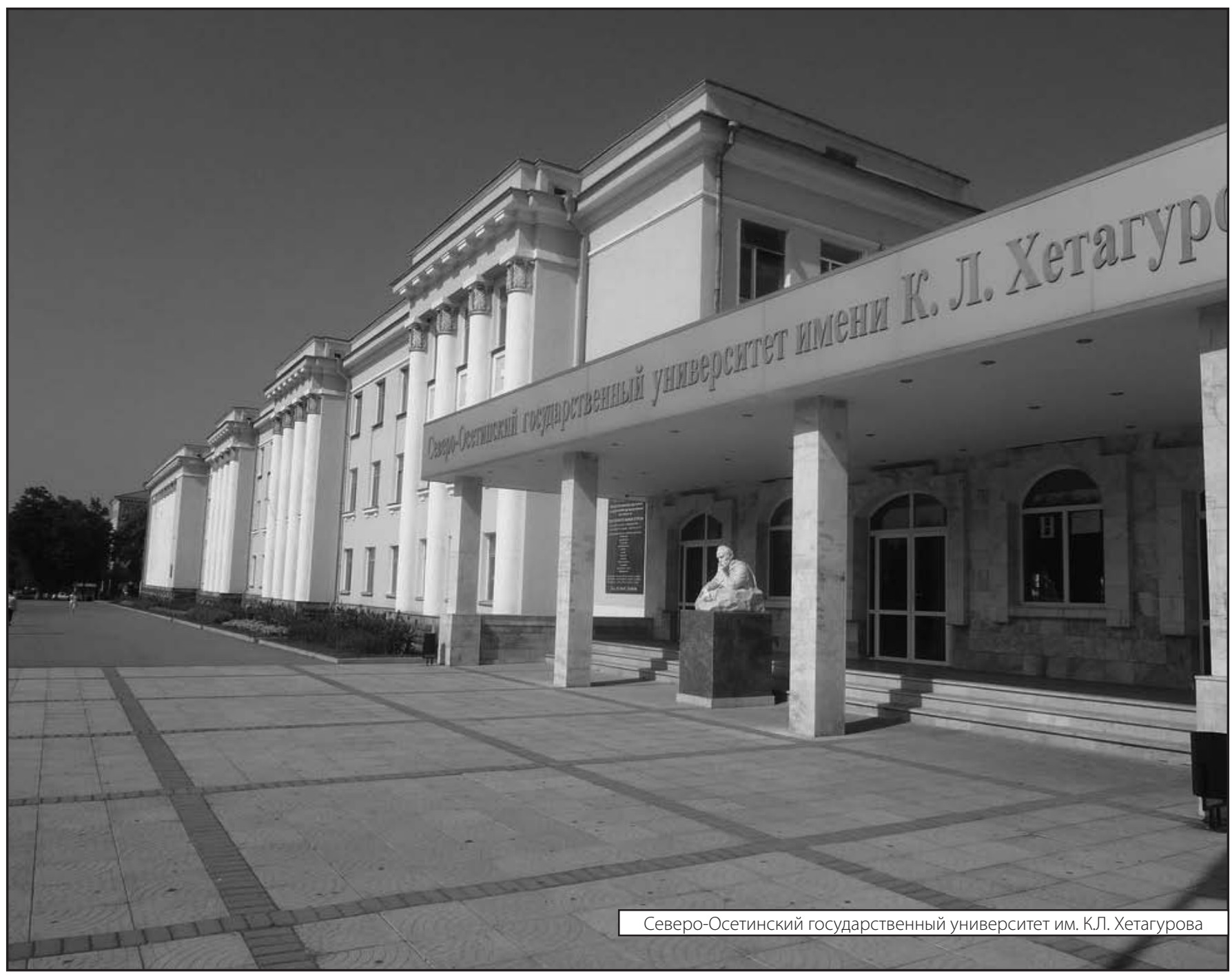

